\title{
ACC-deaminase and/or nitrogen fixing rhizobacteria and growth of wheat (Triticum Aestivum L.)
}

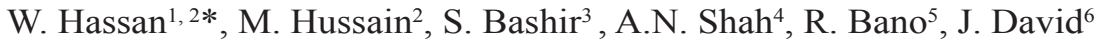 \\ ${ }^{1}$ Humboldt-Universität zu Berlin, 14195, Germany. ${ }^{2}$ College of Agriculture, B.Z.U. Bahadur Campus, Layyah, \\ 31200, Pakistan. ${ }^{3}$ Institute of Soil and Environmental Sciences, University of Agriculture Faisalabad, 38040 \\ Pakistan. ${ }^{4}$ Huazhong Agricultural University, Wuhan, P.R. China, 430070. ${ }^{5}$ On Farm Water Management, \\ Multan, Pakistan. ${ }^{6}$ Freie Universität, Berlin, 14195, Germany. * Corresponding author: wasagr@yahoo.com
}

\begin{abstract}
Plant growth promoting rhizobacteria (PGPR) are beneficial bacteria, which can enhance the growth of the plants, when applied to crops. A pot experiment was conducted to examine the effect of six PGPR isolates on the growth of wheat. Inoculation with rhizobacterial isolates increased the all measured physical, chemical and enzymatic growth parameters compared to control (CK). However, the WAN1 isolate had the highest effect, and significantly $(P<0.05)$ increased the root length $(3.51$-fold $)$, shoot length $(3.22$-fold $)$, seedling fresh (3.41-fold) and dry (3.91-fold) weight, chlorophyll a (3.90-fold), chlorophyll b (3.51-fold), carotenoid contents (7.23-fold), plant macronutrient uptake i.e. N (7.20-fold, 6.71-fold), P (7.41-fold, 5.01-fold), K (5.51-fold, 3.91-fold), Ca (6.40-fold, 5.21-fold) and $\mathrm{Mg}$ (5.82-fold, 7.11-fold) in shoot and root, plant micronutrient uptake i.e. $\mathrm{Zn}$ (6.40fold, 9.11-fold), $\mathrm{Cu}$ (7.31-fold, 7.02-fold), Fe (6.41-fold, 7.52-fold) and Mn (4.57-fold, 5.21-fold) in shoot and root and plant antioxidant enzymes i.e. glutathione S-transferase (7.51-fold), peroxidase (5.21-fold) and catalase (5.01-fold) respectively. Our results revealed that inoculation of agricultural crops with PGPR is a very useful approach to increase the plant growth. The ACC (1-aminocyclopropane-1-carboxylate) enrichment technique is an efficient approach to select promising PGPR. The PGPR containing dual abilities i.e. both ACC-deaminase and nitrogen fixing ability are more effective than PGPR possessing either ACC-deaminase or nitrogen fixing activity alone for growth promotion of crops.
\end{abstract}

Keywords: PGPR, ACC-deaminase, Ethylene and auxin, wheat

\section{Introduction}

Soil microorganisms are vital to agro-ecosystem health via their roles in organic matter decomposition, nutrient cycling and their associations with other organisms and plants i.e. symbiosis (Hassan et al., 2013a; Glick, 2012). In agricultural soils, microorganisms are known to influence profoundly the status of soil fertility and health, and hence crop production (Ahmed and Kibret, 2014;
Hassan et al., 2013a). Different bacterial genera are vital components of soils, as it has been estimated that $80-90 \%$ of the processes in soil are reactions mediated by soil microbes (Hassan and David, 2014). They are involved in various biotic activities of the soil ecosystem to make it dynamic for nutrient turn over and ultimately sustainable crop production (Ahmed and Kibret, 2014). 
The large active groups of bacteria that inhabiting the rhizosphere benefit the crop plants in several ways, collectively called as plant growth promoting rhizobacteria (PGPR) (Hassan et al., 2014a). Interactions between plants and microorganisms in the rhizosphere can clearly affect growth and development of the crop plants and yield (Hassan et al., 2014a; Ahmed and Kibret, 2014). The PGPR can stimulate plant growth indirectly by inhibiting other deleterious microbes, root pathogens, biological control of root crop diseases, by production of antibiotics and siderophores (Ahmed and Kibret, 2014; Hayat et al., 2010). Directly, PGPR provide the plant with a compound that is synthesized by the bacterium or facilitating the uptake of the nutrients (Ahmed and Kibret, 2014; Glick, 2012). Therefore, inoculation of agricultural crops with PGPR result in multiple positive effects on plant e.g. increases in the plant growth and vigor, increment in the chlorophyll, protein, proline and antioxidant enzymes activity and overall biomass of the host plant (Glick, 2012; Hayat et al., 2010). Currently, the biological approaches for improving crop production are gaining strong attention among the agricultural scientists and researchers following integrated plant nutrient management system.

The PGPR synthesize different phytohormones, including auxins, cytokinins, and gibberellins, which can enhance various stages of plant growth; and synthesize enzymes, including phosphatase, catalase, that can modulate plant growth and development, and strengthen their immune system (Glick, 2012). The secretion of a wide range of chemical compounds also modifies the chemical and physical properties of the soil (Ahmed and Kibret, 2014; Glick, 2012). Phytohormone auxin, (indole-3-acetic acid/IAA) is a class of phytohormones which are involved in the regulation of growth and development throughout the life cycle of plants (Ahmed and Kibret, 2014; Etesami et al., 2014). Similarly, Ethylene is also a vital phytohormone, which plays significant roles in the germination and growth and development of the seeds and crop plants (Bhattacharyya and Jha, 2012). Ethylene, produced endogenously by approximately all plants, however, apart from being a plant growth regulator, in excessive amount, ethylene has also been established as a stress hormone (Bhattacharyya and Jha, 2012). Several PGPR are actively involved in the synthesis of auxins in pure culture as well as in soil, and hence can play significant roles in the growth and development of crop plants (Glick, 2012). Alike, the PGPR containing ACC (1-aminocyclopropane-1-carboxylate) deaminase activity is helpful in lowering the ethylene levels by converting ACC into $\mathrm{NH}_{3}$ and $\alpha$-ketobutyrate in plants, and support the plants for vigorous growth and development (Ahmed and Kibret, 2014).

Wheat (Triticum spp.) is one of the most important cereal crops in the world (Schalchli et al., 2012). Globally, it is the most important human staple food grain and ranks second in total production as a cereal crop after maize (FAOSTAT, 2006). In order to meet the demands of the increasing world's population, the use of chemical fertilizers increased significantly (FAOSTAT, 2006). It has been estimated that the total annual fertilizer use has risen from $37 \mathrm{M}$ t of $\mathrm{N}, \mathrm{P}$ and $\mathrm{K}$ in 1961-65 to $161 \mathrm{M}$ $t$ in 2005-09 (FAOSTAT, 2009). The excessive use of chemical fertilizers, drastically increase the pollution in both natural and man made ecosystems (Hassan et al., 2014b). Therefore, it is important to find out other selfpropagating and eco-friendly sources, which can replace the chemical fertilizers entirely or partially (Hassan et al., 2014b). In this regard, the use of PGPR as a biofertilizer is a viable approach. Keeping in view all these challenges, the current study was conducted with the objectives: (1) to isolate and screen the most effective multi-traits PGPR strains for wheat (2) to examine the physical, chemical and enzymatic responses of wheat plant to three different rhizobacterial strains, strain 1: containing ACC-deaminase activity (WACC1, WACC2), strain 2: having nitrogen fixing ability (WRN1, WRN5) 
and strain 3: having both ACC-deaminase activity and nitrogen fixing ability (WAN1, WAN2).

\section{Materials and Methods}

\subsection{Physico-chemical analysis}

The soil was collected at 0-5 cm depth with the help of an augur. The samples were air-dried and passed through 2-mm sieve for further use in the incubation study. Soil texture, $\mathrm{pH}, \mathrm{EC}$ (electrical conductivity), available $\mathrm{P}, \mathrm{N}$, extractable $\mathrm{K}$ and organic matter $(\mathrm{OM})$ and saturation percentage were determined by the methods of Hassan, 2013, Hassan et al., (2013 b, c, d) and Hassan et al., ( $2014 \mathrm{c}, \mathrm{d}, \mathrm{e}$ ). The soil was sandy loam (sand $60.3 \%$, clay $25.5 \%$ and silt $14.2 \%$ ) in texture, and alkaline in nature with saturation percentage $41.5 \%$, pH 7.98, EC 1.71, OM $0.41 \%$, available $\mathrm{P}, \mathrm{N}$ and $\mathrm{K} 8.81,3.67$ and $423 \mathrm{mg} \mathrm{kg}^{-1}$ respectively.

\subsection{Isolation of $P G P R$}

For isolation of bacterial strains, gently rhizosphere soil was collected from tomato crop. Rhizobacteria were isolated by dilution plate technique (Wollum-II, 1982) using Dworkin and Foster (DF) salt minimal media (Dworkin and Foster, 1958). For PGPR containing ACC-deaminase, ACC was the sole nitrogen source. Whereas, modified mannitol agar media was used to isolate PGPR possessing nitrogen fixing activity (Enrichment Technique).

\subsection{Isolation of rhizobacteria containing dual abilities}

Isolated rhizobacteria were further grown on both (DF salt minimal and modified mannitol agar) media to isolate the rhizobacteria containing dual abilities i.e. nitrogen fixing and ACC-deaminase activity. The isolates having ACC-deaminase activity was grown on modified mannitol agar media used for $\mathrm{N}$ fixing isolates and the rhizobacteria possessing $\mathrm{N}$ fixing activity was grown on media used for isolates having ACC-deaminase activity. The isolates WAN1 and WAN2 grew on both media and proved that having both abilities.

\subsection{Preparation of inocula}

Autoclaved $250 \mathrm{ml}$ flasks with DF salt minimal media were used for the preparation of inocula, for the rhizobacterial isolates containing ACC-deaminase activity and modified mannitol agar media for the rhizobacterial isolates having nitrogen fixing activity. The autoclaved flasks were incubated at $28 \pm 1^{\circ} \mathrm{C}$ for 48 hours in the orbital shaking incubator at $100 \mathrm{rpm}$. Optical density was measured carefully to maintain the uniform population of bacteria in the broth at the time of inoculation.

\subsection{Characterization of isolates}

Root colonization was done by the method of Davis and Whitbread, (1989). For this, inoculated seeds were sown in glass jars containing sterilized sand, and the jars were kept in a growth chamber $\left(18{ }^{\circ} \mathrm{C}, 70 \%\right.$ relative humidity, 16 hours daylight). After 7 days of germination, the roots were cut off, dipped in phosphate buffer, and were shaken vigorously to remove the bacteria. After 2 days of incubation at $28^{\circ} \mathrm{C}$ the number of colonies (CFU/cm) was calculated.

For the determination of phosphorus solubilizing activity National Botanical Research Institute's Phosphate growth medium (NBRIP) was used. Rhizobacterial strains were cultured and a loop full of each culture was placed on the plates (five per plate) and incubated at $28^{\circ} \mathrm{C}$ for a week. A clearing zone around the colonies after a week was calculated as a positive for phosphate solubilization 
The formula of Premono et al., (1996) was used for the determination of phosphate solubilizing index (PSI) of these rhizobacterial isolates.

PSI $=\underline{\text { Colony diameter }+ \text { Halozone diameter }}$

Colony diameter

The ACC-deaminase activity was determined by the modified method of Honma and Shimomura, (1978) which measures the amount of $\alpha$-ketobutyrate when the enzyme ACC-deaminase cleaves ACC.

The auxin produced by rhizobacteria as indole acetic acid (IAA) in the presence and absence of L-tryptophan (L-TRP) was essayed by the method of Sarwar et al., (1992). Some pertinent characteristics of the rhizobacterial isolates are shown in Table 1.

Table 1. Characterization of rhizobacterial strains

\begin{tabular}{|c|c|c|c|c|c|c|c|}
\hline \multirow{2}{*}{$\begin{array}{c}\text { PGPR } \\
\text { isolates }\end{array}$} & \multirow{2}{*}{$\begin{array}{c}\text { ACC-deaminase activity } \\
\text { ( } \mu \text { mol } \alpha \text {-ketobutyrate g- } \\
\text { biomass } 1 / 2 \mathrm{~h}^{-1} \text { ) }\end{array}$} & \multirow{2}{*}{$\begin{array}{c}\text { Nitrogen fixing } \\
\text { activity }\end{array}$} & \multirow{2}{*}{$\begin{array}{l}\text { Phosphorous } \\
\text { solubilization }\end{array}$} & \multicolumn{2}{|c|}{ IAA production $\mathrm{mg} \mathrm{L}^{-1}$} & \multirow{2}{*}{$\begin{array}{c}\text { Root } \\
\text { colonization } \\
\text { CFU } \text { g }^{-1} \text { root }\end{array}$} & \multirow{2}{*}{$\begin{array}{c}\text { Phosphate } \\
\text { solubilizing } \\
\text { index } \\
\text { (PSI) }\end{array}$} \\
\hline & & & & With L-TRP & Without L-TRP & & \\
\hline WACC1 & 20.5 & -ve & $+\mathrm{ve}$ & 18.8 & 11.5 & $3.5 \times 10^{7}$ & $1.73 \pm 0.13$ \\
\hline WACC2 & 17.8 & -ve & -ve & 10.1 & 7.12 & $2.1 \times 10^{7}$ & - \\
\hline WAN1 & 10.2 & $+\mathrm{ve}$ & $+\mathrm{ve}$ & 28.8 & 8.22 & $12.4 \times 10^{7}$ & $4.18 \pm 0.16$ \\
\hline WAN2 & 8.11 & $+\mathrm{ve}$ & $+\mathrm{ve}$ & 23.5 & 5.15 & $9.7 \times 10^{7}$ & $2.81 \pm 0.14$ \\
\hline WRN1 & 0.0006 & $+\mathrm{ve}$ & -ve & 14.3 & 9.71 & $7.3 \times 10^{7}$ & - \\
\hline WRN5 & 0.0004 & $+\mathrm{ve}$ & $+\mathrm{ve}$ & 7.96 & 4.29 & $4.9 \times 10^{7}$ & $1.11 \pm 0.11$ \\
\hline
\end{tabular}

-ve $=$ Absent

$+\mathrm{ve}=$ Present

\subsection{Determination of plant physical parameters}

The fresh and dry weight of the shoots and roots were determined with the help of an analytical balance. For dry weight plants were oven dried at $70{ }^{\circ} \mathrm{C}$.

\subsection{Determination of chlorophyll and carotenoids}

The method of Arnon, (1949) was used for the determination of chlorophyll and carotenoid contents in the acetone extract $(80 \% \mathrm{v} / \mathrm{v})$ at 663,645 and 480 $\mathrm{nm}$ for chlorophyll a, b and carotenoid, respectively.

\subsection{Macro and micronutrients in plant}

The $\mathrm{H}_{2} \mathrm{SO}_{4}$ titration method was used for the plant nitrogen $(\mathrm{N})$ determination (Van-Schouwengerg and Walinge, 1973). For the measurement of the plant phosphorous (P) the method of Buresh et al., (1982) was followed. The plant potassium (K) was determined by using the dry ashing method (Chapman and Pratt, 1961). The micronutrients i.e. $\mathrm{Ca}^{+2}, \mathrm{Mg}^{+2}$, $\mathrm{Mn}^{+2}, \mathrm{Zn}^{+2}, \mathrm{Cu}^{+2}$ and $\mathrm{Fe}^{+3}$ were determined by atomic absorption spectroscopy after dry ashing (Chapman and Pratt, 1961). 


\subsection{Plant enzymes activity}

For enzymes activity analyses plant samples were prepared by homogenizing $0.5 \mathrm{~g}$ of frozen leaf material in $3 \mathrm{ml}$ of cold solution containing $50 \times 10^{-3} \mathrm{M} \mathrm{Na}$ phosphate buffer $(\mathrm{pH} 7.8), 1 \times 10^{-3}$ $\mathrm{M}$ Ethylenediaminetetraacetic acid and 2\%(w/v) Polyvinylpolypyrrolidone. The homogenate was centrifuged at $0{ }^{\circ} \mathrm{C}$ for 40 minutes at $13000 \mathrm{~g}$. The glutathione S-transferase (GST) was essayed by the method of Habig et al., (1974). The method of Nakano and Azada, (1987) was used for the spectrophotometric determination of peroxidase (POX) activity. Whereas, the spectrophotometric determination of catalase (Cata) activity was done by the method of Cakmak and Horst, (1991).

\subsection{Experimental design}

Two PGPR isolates (WACC1 and WACC2) containing ACC-deaminase activity, two PGPR isolates (WRN1 and WRN5) having nitrogen fixing activity and two PGPR isolates (WAN1 and WAN2) possessing both ACC-deaminase and nitrogen fixing activity were selected for incubation experiment. The inoculum for trial was prepared by growing the selected PGPR isolates. For inoculation of treatments, germinated seeds (variety Uqab-2000) were dipped in broth having selected ACC-deaminase and/or nitrogen fixing isolates. For control treatments, the wheat seeds were dipped in sterilized flasks containing $0.03 \mathrm{M}$ $\mathrm{MgSO}_{4}$. Four inoculated seeds were sown in each pot having $500 \mathrm{~g}$ soil/pot. Sterilized $1 / 2$ strength nitrogen free Hoagland solution was used to provide nutrients to growing seedling. There were four replications for each treatment. Pots were arranged in complete randomized design (CRD) in a growth room under axenic conditions. After 28 days of germination, wheat plants were harvested and parameters regarding root and shoot length, seedling fresh and dry weight, chlorophyll a, b and carotenoid contents, macro and micro nutrients in plant shoot and root and antioxidant enzymes glutathione S-transferase, peroxidase and catalase activities were recorded.

\subsection{Statistical analysis}

The data were statistically analyzed by Statistix 8.1 statistical package (Statistix, USA). Parametric statistics of ANOVA analysis was carried out to estimate the effect of rhizobacterial isolate inoculation on plant growth. Mean separations were achieved using a least significant difference (LSD) test at $p<0.05$.

\section{Results}

\subsection{Root and shoot length}

The inoculation of wheat seedlings with rhizobacterial isolates containing nitrogen fixing and/or ACC-deaminase activity increased the root and shoot length as compared to uninoculated control. The root and shoot length ranged from 1.51 -fold to 3.51 -fold and 1.40 to 3.22 fold under normal growth conditions (Figure 1). The isolate WAN1 showed maximum increase in the root and shoot length that was 3.51-fold and 3.22fold respectively as compared to uninoculated control. Conversely, WAN2 was the next effective isolate in promoting root and shoot length (3.1fold and 2.91-fold) as compared to uninoculated control. The other isolates namely, WRN1, WRN5, WACC1 and WACC2 caused 2.51-fold, 2.21-fold, 2.22-fold, 1.91-fold, 1.81-fold, 1.61-fold and 1.51fold and 1.40-fold increase in root and shoot length as compared to uninoculated control. 


\subsection{Fresh and dry weight of seedlings}

The effect of inoculation with either ACCdeaminase and/or nitrogen fixing activity possessing rhizobacteria on the fresh and dry weight of seedling is shown in Figure 2. Data showed that fresh and dry weight of seedlings increased significantly $(P<0.05)$ as a result of inoculation, ranged from 1.51 to 3.41 fold and 1.60 to 3.91 fold. All rhizobacterial isolates caused significant $(P<0.05)$ increase in the fresh weight of seedlings. Nevertheless the WAN1 was the most efficient isolate, caused an increase of 3.41-fold and 3.91-fold. The WAN2 was the second best isolate, caused an increase of 3.11-fold and 3.41-fold. The next effective isolates were WRN1, WRN5, WACC1 and WACC2 that resulted in about 2.61-fold and 2.92fold, 2.41-fold and 2.61-fold, 1.81-fold and 2.21-fold and 1.51-fold and 1.60-fold increase respectively.

\subsection{Chlorophyll $a, b$ and carotenoid contents}

The inoculation with either ACC-deaminase and/ or nitrogen fixing activity containing rhizobacteria significantly $(P<0.05)$ increased the chlorophyll $\mathrm{a}, \mathrm{b}$ and carotenoid contents. The increase in the chlorophyll a, b and carotenoid contents ranged from 1.63 to 3.91 fold, 1.61 to 3.51 fold and 1.81 to 7.21 fold (Figure 3). Isolate WAN1 was found to be the most effective that caused 3.91-fold, 3.51-fold and 7.21-fold increase in chlorophyll a, b and carotenoid contents over uninoculated control respectively. The next effective isolates were WAN2, WRN1, WRN5, WACC1 and WACC2 that resulted in about 3.41-fold, 3.20-fold, 6.01-fold, 3.01-fold, 2.61-fold, 4.91-fold, 2.61-fold, 2.30-fold, 3.41-fold, 1.91-fold, 1.90-fold, 2.62-fold, and 1.63-fold, 1.60-fold and 1.81-fold increase in chlorophyll a, b and carotenoid contents respectively, compared to uninoculated control.

\subsection{Macronutrient contents in shoot and root}

Data showed that inoculation with rhizobacteria containing either ACC-deaminase and/or nitrogen fixing activity increased the plant ionic uptake e.g. macronutrient contents ( $\mathrm{N}, \mathrm{P}, \mathrm{K}, \mathrm{Ca}$, and $\mathrm{Mg}$ ) in shoot and root (Figure 4). Among all isolates the maximum N (7.11-fold and 6.71-fold), P (7.41-fold and 4.90fold), K (5.51-fold and 3.90-fold), Ca (6.40-fold and 5.21-fold) and $\mathrm{Mg}$ (5.80-fold and 7.01-fold) contents in plant shoot and root were found in WAN1. The other isolates namely WAN2, WRN1, WRN5, WACC1 and WACC2 also significantly $(P<0.05)$ increased the $\mathrm{N}$ (5.81-fold, 5.11-fold, 3.62-fold, 2.61-fold and 1.90fold), P (5.81-fold, 4.62-fold, 3.61-fold, 2.80-fold and 2.01-fold), K (4.61-fold, 3.71-fold, 2.91-fold, 2.03fold and 1.61-fold), Ca (4.40-fold, 3.71-fold, 3.30fold, 2.71-fold and 2.31-fold) and $\mathrm{Mg}$ (4.51-fold, 4.01-fold, 3.21-fold, 2.61-fold and 1.71-fold) in the plant shoot compared to control. Similarly, the other isolates namely WAN2, WRN1, WRN5, WACC1 and WACC2 also significantly $(P<0.05)$ increased the $\mathrm{N}$ (5.11-fold, 4.01-folds, 3.31-fold, 2.71-fold and 2.30fold), P (4.30-fold, 3.60-fold, 3.31-fold, 2.91-fold and 2.61-fold), K (3.21-fold, 2.50-fold, 1.91-fold, 1.72fold and 1.41-fold), Ca (4.41-fold, 3.61-fold, 3.01fold, 2.41-fold and 1.80-fold) and $\mathrm{Mg}$ (6.11-fold, 5.61-fold, 4.50-fold, 3.70-fold and 1.91-fold) in the plant root compared to control.

\subsection{Micronutrient contents in shoot and root}

Data showed that inoculation with rhizobacteria containing either ACC-deaminase and/or nitrogen fixing activity increased the plant ionic uptake e.g. micronutrient contents ( $\mathrm{Zn}, \mathrm{Cu}, \mathrm{Fe}$ and $\mathrm{Mn}$ ) in shoot and root (Figure 5). Among all isolates the maximum Zn (6.41-fold and 9.11-fold), Cu (7.31-fold and 7.01- 
fold), Fe (6.40-fold and 7.51-fold) and Mn (4.50-fold and 5.20-fold) contents in plant shoot and roots were found in treatments inoculated with WAN1. The other isolates namely WAN2, WRN1, WRN5, WACC1 and WACC2 also significantly $(\mathrm{P}<0.05)$ increased the $\mathrm{Zn}$ (5.60-fold, 4.61-fold, 3.70-fold, 2.81-fold and 1.90fold), $\mathrm{Cu}$ (6.01-fold, 4.41-fold, 3.30-fold, 2.51-fold and 1.70-fold), Fe (5.31-fold, 4.20-fold, 3.41-fold, 2.70-fold and 1.90-fold) and $\mathrm{Mn}$ (3.90-fold, 3.31-fold, 2.81-fold, 2.41-fold and 1.90-fold) contents in the plant shoot compared to control. Similarly, the other isolates namely WAN2, WRN1, WRN5, WACC1 and WACC2 also significantly $(p<0.05)$ increased the $\mathrm{Zn}$ (7.80-fold, 6.10-fold, 4.71-fold, 3.31-fold and 1.91fold), $\mathrm{Cu}$ (5.20-fold, 4.01-fold, 2.91-fold, 1.90-fold and 1.31-fold), Fe (6.01-fold, 5.01-fold, 3.80-fold, 2.71-fold and 1.60-fold) and Mn (4.41-fold, 3.71fold, 3.01-fold, 2.60-fold and 2.01-fold) contents in the plant root compared to control.

\subsection{Glutathione S-transferase, peroxidase and catalase activity}

The inoculation with rhizobacteria containing either ACC-deaminase and/or nitrogen fixing activity significantly $(P<0.05)$ increased the GST, POX and Cata activity (Figure 6). All rhizobacterial isolates showed increase in the GST, POX and Cata activity. Nevertheless the isolate WAN1 was the most effective and showed highest increase in the GST, POX and Cata activity i.e. 7.51-fold, 5.31-fold and 5.01-fold. The WAN2, WRN1 and WRN5 were the next best effective rhizobacterial isolates and caused an increase of 5.51-fold, 4.21-fold and 4.01-fold, 4.10-fold, 3.20-fold and 3.41-fold, 3.01-fold, 2.60fold and 2.81-fold in the GST, POX and Cata activity respectively. Whereas, WACC1 and WACC2 showed minimum increase in the GST, POX and Cata activity comparing with other rhizobacterial isolates i.e. 2.20- fold, 2.01-fold and 2.21-fold, and 1.41-fold, 1.50-fold and 1.48 -fold correspondingly.

\subsection{Characteristics of isolates}

Some pertinent characteristics of rhizobial isolates used in the experiment are given in Table 1. It was observed that, among all isolates, WAN1 had maximum root colonization activity i.e. $11.7 \times 10^{7}$ and produced more auxin $\left(30.1 \mathrm{mg} \mathrm{l}^{-1}\right)$ in the presence of L-TRP. Conversely, WACC1 had maximum ACCdeaminase activity i.e. $18.58 \mu \mathrm{mol} \alpha$-ketobutyrate g-biomass $1 / 2 \mathrm{~h}^{-1}$.

\section{Discussion}

Inoculation with rhizobacterial isolate containing ACC-deaminase and/or nitrogen fixing activity significantly $(P<0.05)$ increased the root and shoot length, and fresh and dry weight of the seedlings compared to uninoculated control. Comparing the effect of rhizobacterial isolates, the WAN1 showed maximum root and shoot length, and fresh and dry weight of the seedlings than other isolates and uninoculated control (Figures 1-2). The effect of other rhizobacterial isolates was in the order WAN2 $>$ WRN1 $>$ WRN5 $>$ WACC1 $>$ WACC2. It has been reported that certain microorganisms contain an enzyme ACCdeaminase that hydrolyzed the ACC into $\mathrm{NH}_{3}$ and $\alpha$-ketobutyrate, and reduced the inhibitory effects of ethylene for vigorous growth of plants i.e. rootshoot length and fresh and dry weights (Mayak et al., 2004). Shaharoona et al., (2003) investigated the effect of ACC-deaminase possessing rhizobacteria on the growth of maize seedlings, and found significant increase in the root and shoot lengths and fresh and dry weights of maize seedlings over uninoculated control. The reason of the WAN1 being the best rhizobacterial isolate was, having both nitrogen fixing and ACC- 
deaminase activities and maximum root colonization ability. It was found that rhizobacterial isolate having both nitrogen fixing and ACC-deaminase activities showed more promising effects on agricultural plants, and increase the plant growth, root and shoot length, and fresh and dry weights due to its maximum root colonization activity, and ability to minimize the endogenous levels of ethylene synthesis (Glick, 2012; Shaharoona et al., 2003).

The data of chlorophyll a, b and carotenoid contents showed that among all experimental isolates again WAN1 showed significant $(\mathrm{P}<0.05)$ increase in chlorophyll a, b and carotenoid contents compared to other rhizobacterial isolates and uninoculated control (Figure 3). The overall effect of other isolates was in the order of WAN2 $>$ WRN1 > WRN5 $>$ WACC1 $>$ WACC2. Yet again isolate having both ACC-deaminase and nitrogen fixing activities i.e. WAN1 proved to be the best than isolates either having nitrogen fixing activity or ACC-deaminase activity alone. Stefan et al., (2013) found that the PGPR strains (S4 and S7), alone or in combination, significantly increased the chlorophyll and carotenoid contents of the runner bean. Mia et al., (2010) revealed that inoculation with rhizobacterial strains (Sp7 and UPMB10) significantly increased the growth attributes e.g. leaf area, chlorophyll and carotenoid contents.

The significant increase $(P<0.05)$ in the plant ionic uptake e.g. macronutrient $(\mathrm{N}, \mathrm{P}, \mathrm{K}, \mathrm{Ca}$ and $\mathrm{Mg}$ ) and micronutrients ( $\mathrm{Zn}, \mathrm{Cu}, \mathrm{Fe}$ and $\mathrm{Mn})$ in the shoot and root was observed after inoculation with rhizobacterial isolates (Figures 4-5). Among the rhizobacterial isolates WAN1 was the most effective isolate and caused highest increase in the macro and micronutrient contents of the plant shoot and root. The efficacy of other rhizobacterial isolates was in the following order WAN2 $>$ WRN1 $>$ WRN5 $>$ WACC1 $>$ WACC2. Sahran and Nehra, (2011) concluded that inoculation with PGPR significantly increased the plant mineral $(\mathrm{N}, \mathrm{P}, \mathrm{K}, \mathrm{Ca}, \mathrm{Mg})$ consumption. Hayat et al., (2010) concluded that growth promoting rhizobacteria increase the mobility and availability of plant nutrients in the soil, and as a result increase the nutrient uptake of the plants. Nadeem et al., (2006) concluded that inoculation with PGPR significantly increase the plant ionic consumption i.e. N, P and K in the shoot and root of the maize plant.

The data of plant enzymes activity showed (Figure 6) that inoculation with rhizobacterial isolates considerably $(P<0.05)$ enhanced the antioxidant plant enzymes activity i.e. glutathione S-transferase, peroxidase and catalase activities. All rhizobacterial isolates had positive effect on plant enzymes activity, however the WAN1 was found to be the best. The effect of other rhizobacterial isolates was in the order WAN2 > WRN1 > WRN5 > WACC1 > WACC2. Stefan et al., (2013) observed that the PGPR strains (S4 and S7), alone or in combination, considerably increased the activity of superoxide dismutase and peroxidase enzymes. Mia et al., (2010) found that rhizobacterial inoculation ( $\mathrm{Sp} 7$ and UPMB10) significantly increased the nitrogen uptake in plants which ultimately increased the formation of protein and enzyme for better physiological activities. Hayat et al., (2010) stated that PGPR increase the plant vigor and decrease the biotic and abiotic stresses by producing different anti-oxidant enzymes.

Results of isolates characteristics clearly revealed that among all isolates, WAN1 had maximum root colonization activity and produced more auxin in the presence of L-TRP, whereas, WACC1 had maximum ACC-deaminase activity among all rhizobacterial isolates (Table 1). The difference in plant growth promotion by different rhizobacterial isolates may be due to the differences in their efficiency of colonizing the germinating roots, production of plant hormones (e.g. auxin) and ability to hydrolyze the 
ACC in plant roots (Hassan et al., 2014). It has been reported that traits e.g. production of IAA, auxin, phosphate solubilization and chitin production by PGPR are helpful for better nutrient mobilization and availability for plants, as a result inoculation with rhizobacteria containing ACC-deaminase could result in the development of much better germination of seeds and longer roots, which subsequently affects over all growth of the host plant (Zafarul-Hye et al., 2007). Phosphate solubilization, dinitrogen fixation, ACC-deaminase and antifungal activity, IAA and siderophore biosynthesis characteristics of PGPR are responsible for the plant growth promotion and high yield (Ahmed and Kibret, 2014).
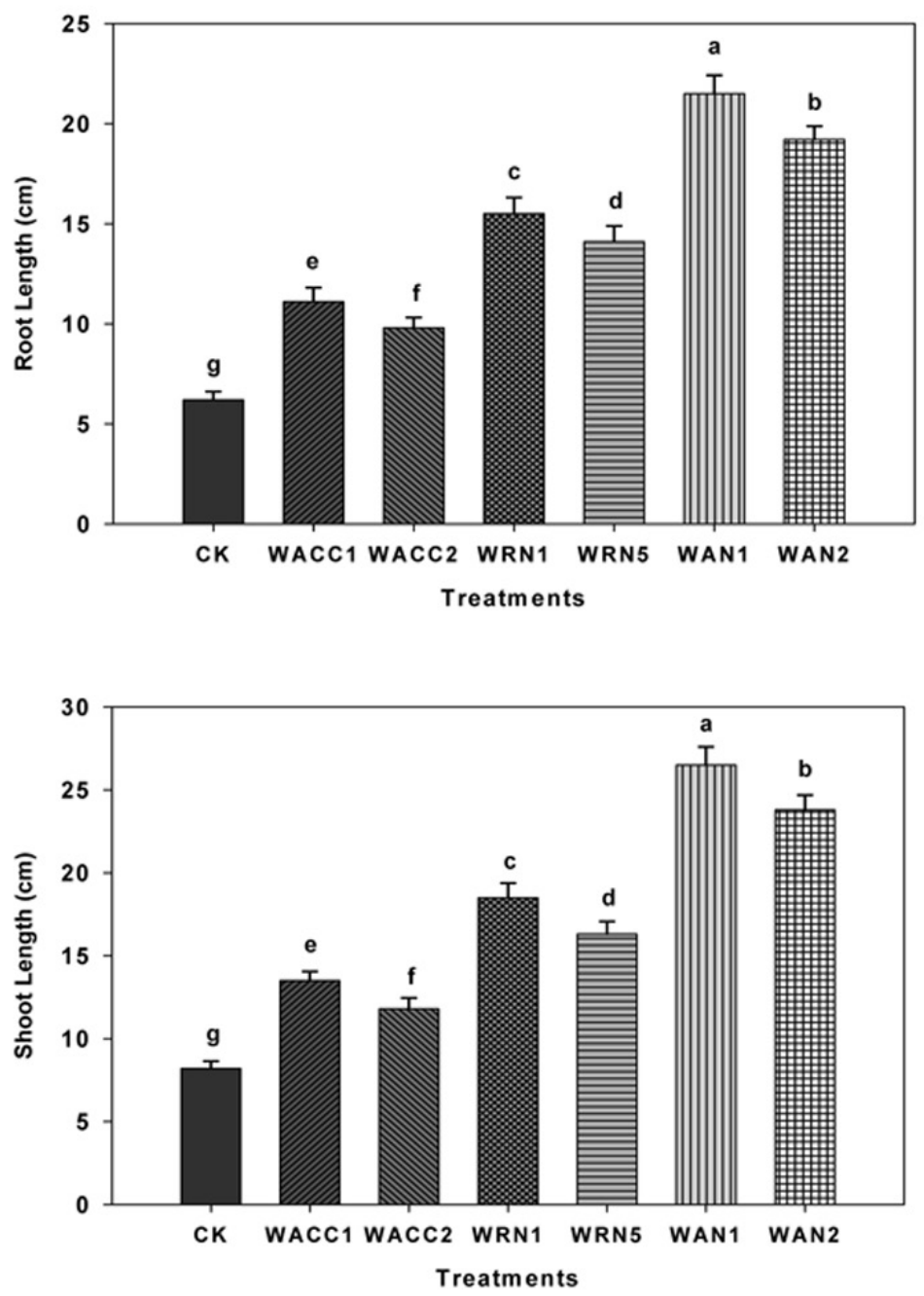

Figure 1. Comparative effectiveness of ACC-deaminase and/or nitrogen fixing rhizobacteria on root and shoot length of wheat. Different letters (a-g) on bars indicate significant differences of mean values for root length. Bars represent standard errors.

$\mathrm{CK}=$ Control 

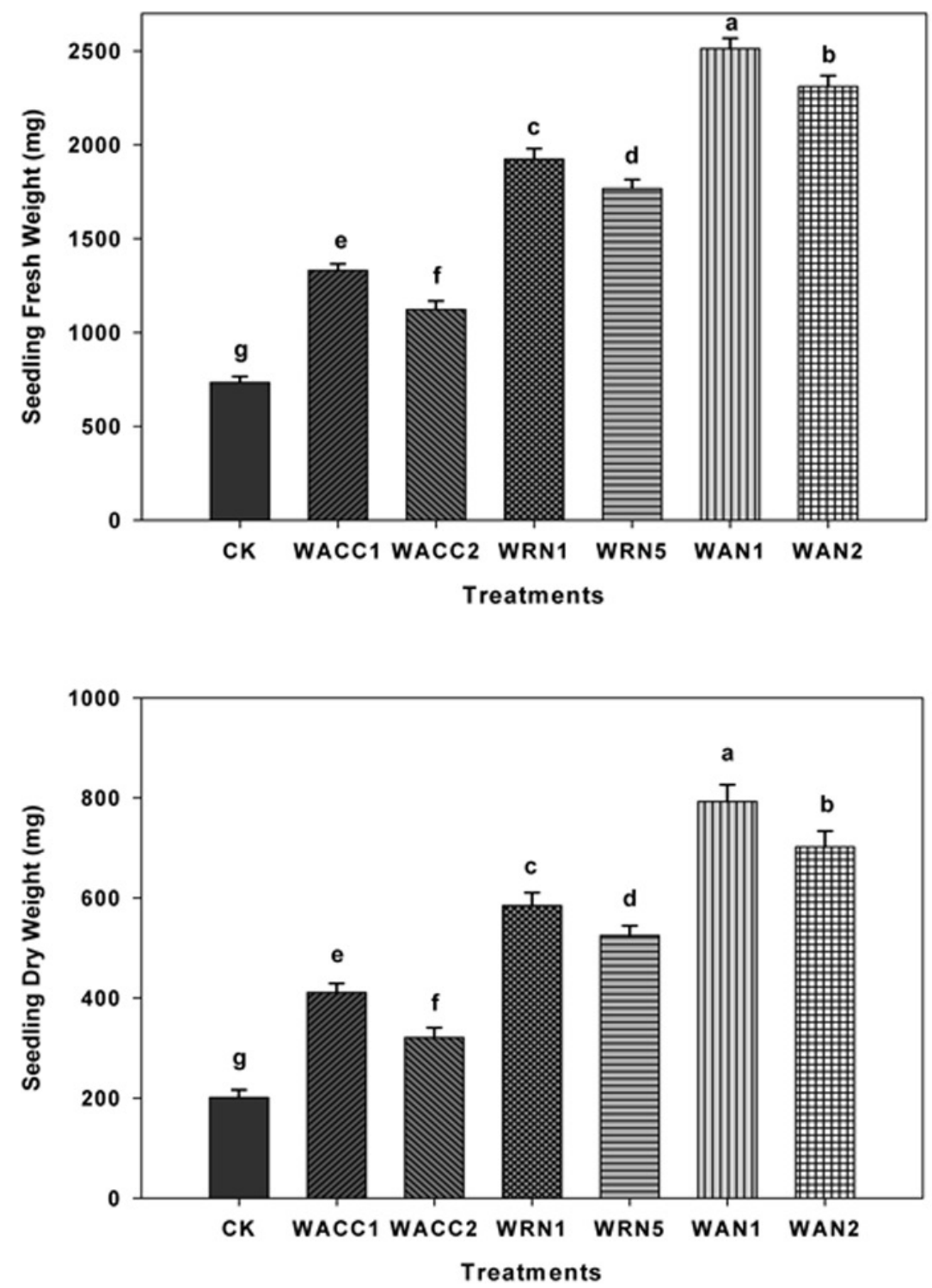

Figure 2. ComparativeeffectivenessofACC-deaminaseand/ornitrogenfixingrhizobacteriaonseedlingfreshanddryweightofwheat. Different letters (a-g) on bars indicate significant differences of mean values for seedling fresh weight. Bars representstandard errors.

$\mathrm{CK}=$ Control 

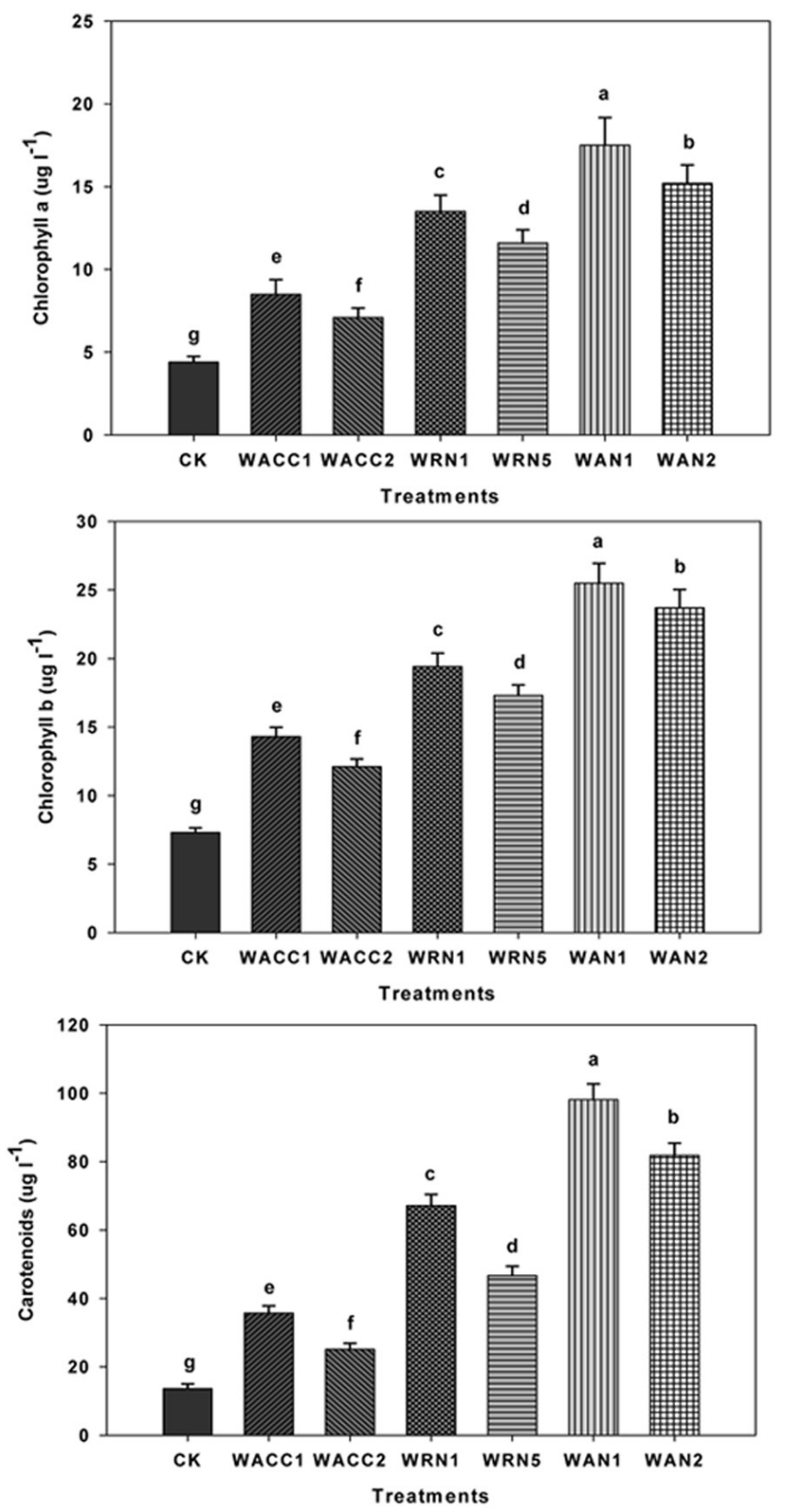

Figure 3. Comparative effectiveness of ACC-deaminase and/or nitrogen fixing rhizobacteria on chlorophyll a, $\mathrm{b}$ and carotenoid contents of wheat. Different letters (a-g) on bars indicate significant differences of mean values for chlorophyll a contents. Bars represent standard errors.

$\mathrm{CK}=$ Control 

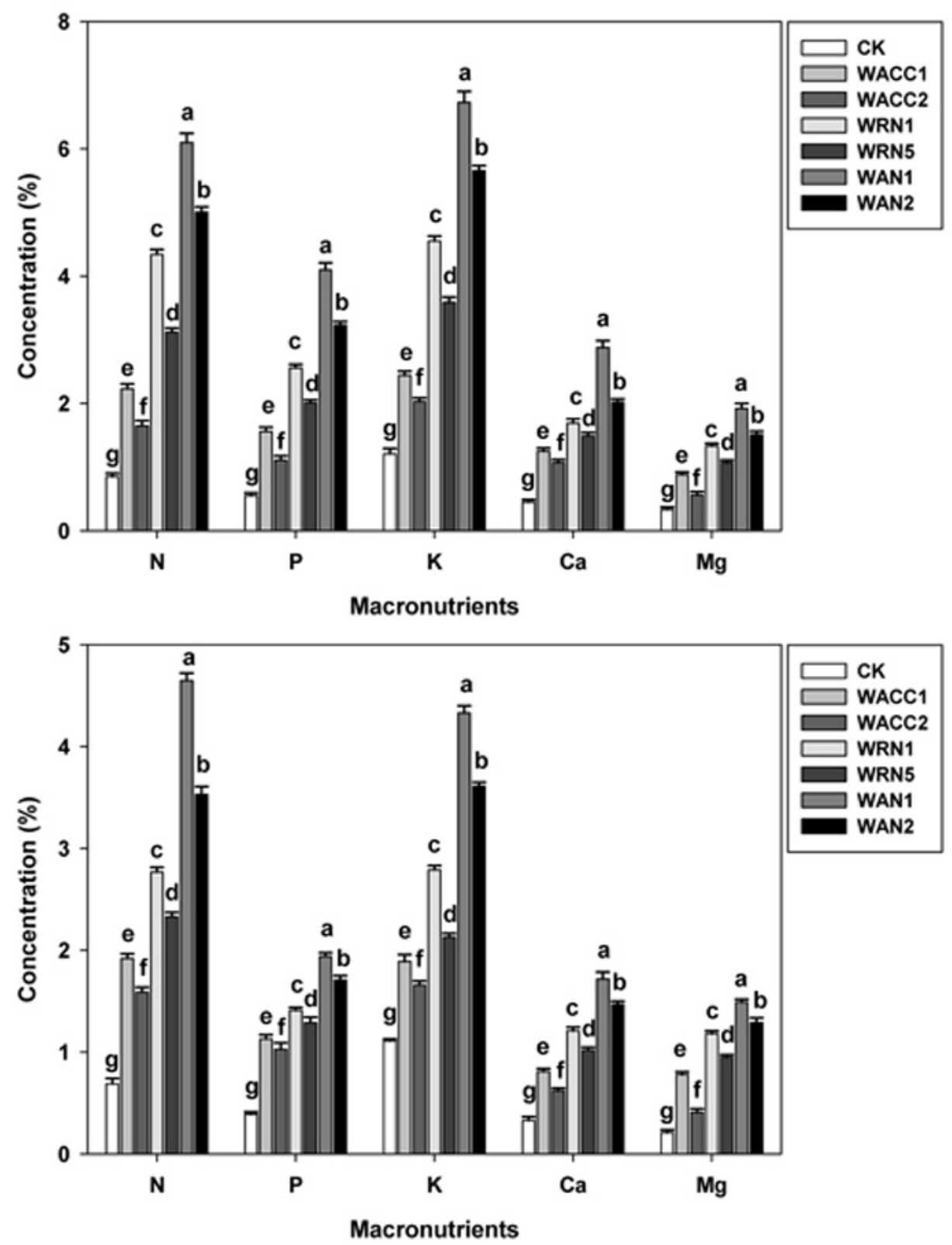

Figure 4. Comparative effectiveness of ACC-deaminase and/or nitrogen fixing rhizobacteria on macronutrient contents (N, $\mathrm{P}$, $\mathrm{K}, \mathrm{Ca}$, and $\mathrm{Mg}$ ) in shoot and root of wheat. Different letters $(\mathrm{a}-\mathrm{g})$ on bars indicate significant differences of mean values for macronutrient contents. Bars represent standard errors.

$\mathrm{CK}=$ Control 

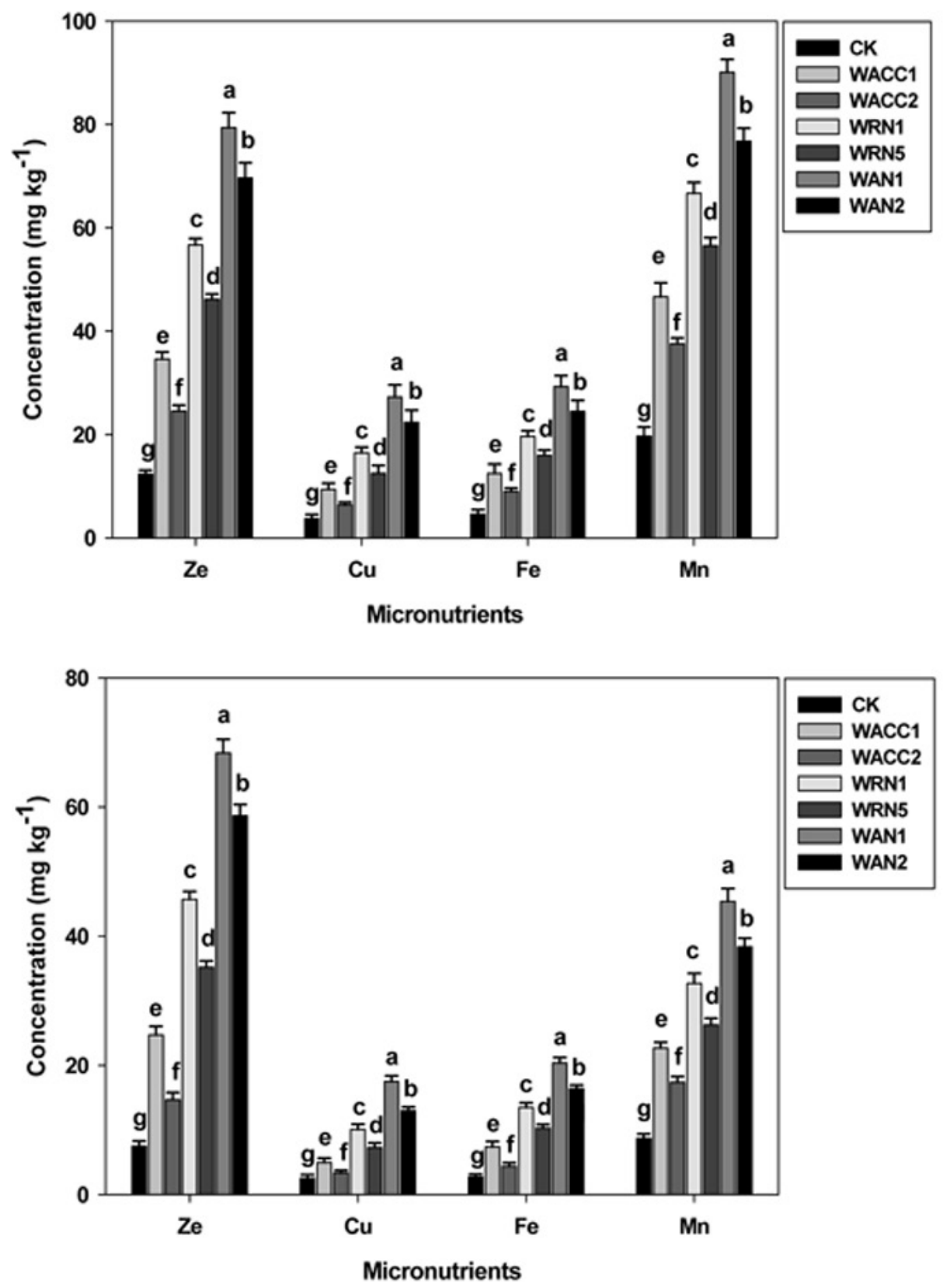

Figure 5. Comparative effectiveness of ACC-deaminase and/or nitrogen fixing rhizobacteria on micronutrient contents ( $\mathrm{Zn}$, $\mathrm{Cu}, \mathrm{Fe}$ and $\mathrm{Mn}$ ) in shoot and root of wheat. Different letters (a-g) on bars indicate significant differences of mean values for micronutrient contents. Bars represent standard errors.

$\mathrm{CK}=$ Control 

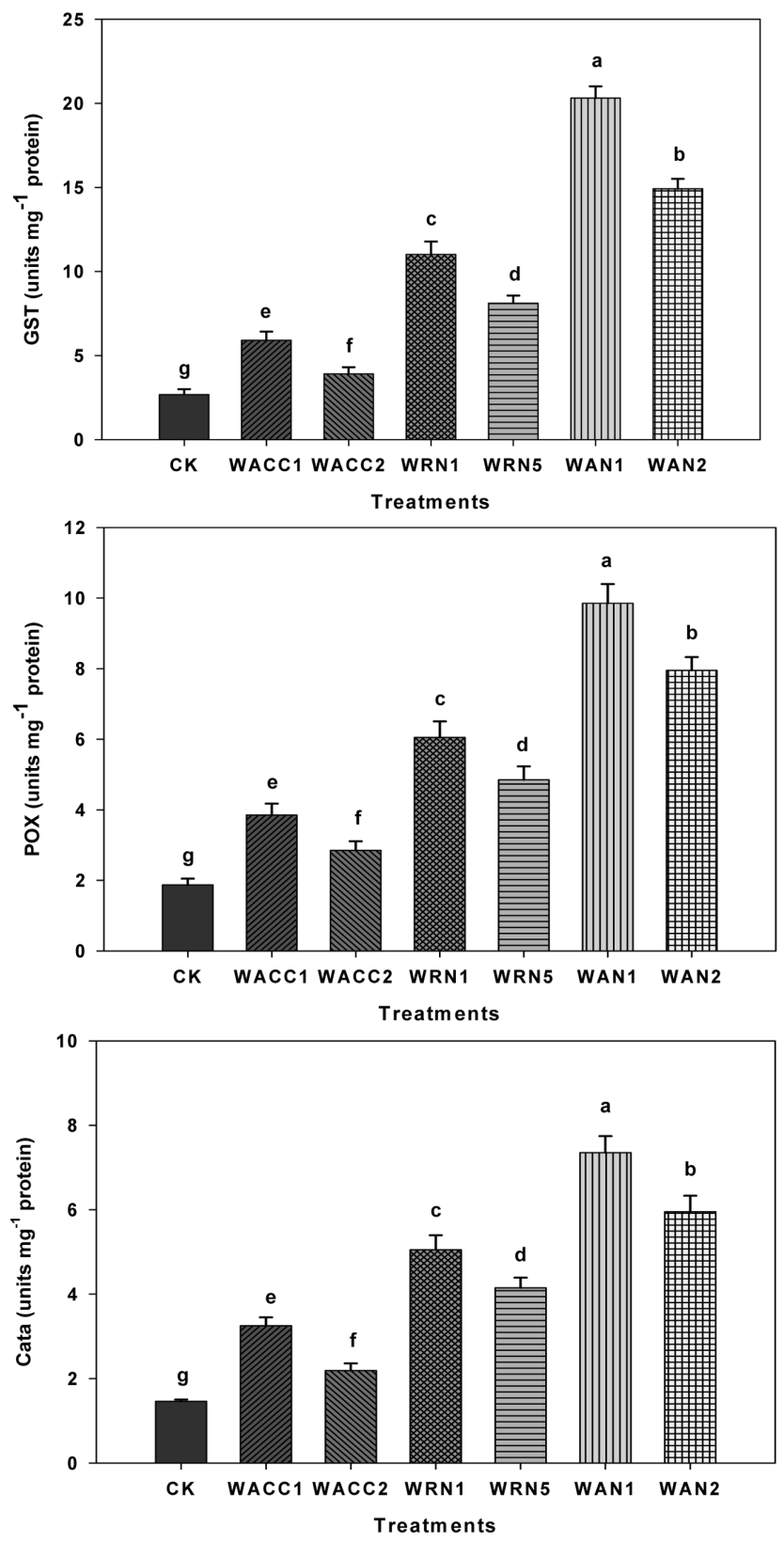

Figure 6. Comparative effectiveness of ACC-deaminase and/or nitrogen fixing rhizobacteria on enzymes GST, POX and Cata activity. Different letters (a-g) on bars indicate significant differences of mean values for glutathione S-transferase activity. Bars represent standard errors.

$\mathrm{CK}=$ Control; $\mathrm{GST}=$ glutathione $\mathrm{S}$-transferase POX $=$ peroxidase Cata $=$ Catalase 


\section{Conclusions}

Inoculation of agricultural crops with rhizobacterial strains is a very viable and eco-friendly approach to increase crop production on sustainable basis. The plant-beneficial rhizobacteria may decrease the global dependence on hazardous agricultural chemicals which destabilize the agro-ecosystems. PGPR protect the plants from the deleterious effects of biotic and abiotic stresses by producing phytohormones and antioxidant enzymes and increase the plant growth by increasing the nutrients availability and uptake. The ACC enrichment technique is an effective and efficient approach to select most promising PGPR. Rhizobacteria containing both ACC-deaminase and nitrogen fixing activity are more effective than rhizobacteria containing either ACC-deaminase or nitrogen fixing activity alone for growth promotion of agricultural crops.

\section{References}

Ahemad, M., Kibret, M. 2014. Mechanisms and applications of plant growth promoting rhizobacteria: Current perspective. J. King Saud Uni. Sci. 26, 1-20.

Arnon, D.I. 1949. Copper induced enzyme in isolated chloroplasts; polyphenol oxidase in beta vulgaris. Plant Physiol. 24, 1-15.

Bhattacharyya, P.N., Jha, D.K., 2012. Plant growthpromoting rhizobacteria (PGPR): emergence in agriculture. World J. Microbiol. Biotechnol. 28, 1327-1350.

Buresh, R.J., Austin, E.R., Craswell, E.T. 1982. Analytical methods in n-15 research. Fert. Res. 3, 37-62.
Cakmak, I., Horst, W.J. 1991. Effect of aluminium on lipid peroxidation, superoxidase dismutase, catalase and peroxidase activities in root tips of soybean (Glycine max). Physiologia Plantarum. 83, 463-468.

Chapman, H.D., Pratt, P.F. 1961. Methods of analysis for soils, plants and water. Univ. California, Berkeley, CA, USA.

Davies, K.G, Whitbread, R.A. 1989. Comparison of method for measuring the colonization of root system by fluorescent pseudomonads. Plant Soil. 116, 239-246.

Dworken, M., Foster, J. 1958. Experiment with some microorganisms which utilize ethane and hydrogen. J. Bacteriol. 75, 92-601.

Etesami, H., Hosseini, M., Alikhani, H.A. 2014. In planta selection of plant growth promoting endophytic bacteria for rice (Oryza sative L.). J. Soil Sci. Plant Nut. 14, 491-503.

FAOSTAT database of World Agriculture 2006. Food and Agriculture Organization of the United Nations Statistics Division.

FAOSTAT database of World Agriculture 2009. Food and Agriculture Organization of the United Nations Statistics Division.

Glick, B.R. 2012. Plant Growth-Promoting Bacteria: Mechanisms and Applications. Hindawi Publishing Corporation, Scientifica.

Habig, W.H., Pabst, M.J., Jakoby, W.B. 1974. Glutathion S-Transferases, the first enzymatic step in mercapturic acid formation. The J. Biol. Chem. 249, 7130-7139.

Hassan, W., Chen, W., Huang, Q., Mohamed, I. 2013a. Microcalorimetric evaluation of soil microbiological properties under plant residues and dogmatic water gradients in Red soil. Soil Sci. Plant Nut. 59, 858-870. 
Hassan, W., Akmal, M., Muhammad, I., Younas, M., Zahaid, K.R., Ali, F. 2013b. Response of soil microbial biomass and enzymes activity to cadmium (Cd) toxicity under different soil textures and incubation times. Aust. J. Crop Sci. 7, 674-680.

Hassan, W., Chen, W., Cai, P., Huang, Q. 2013c. Oxidative enzymes, the ultimate regulator: implications for factors affecting their efficiency. J. Environ. Qual. 42, 1779-1790.

Hassan, W. 2013d. C and N mineralization and dissolved organic matter potentials of two contrasting plant residues: effects of residue type, moisture and temperature. Acta Agr. Scand. B-S P. 63, 642-652.

Hassan, W., David, J. 2014. Effect of lead pollution on soil microbiological index under spinach (Spinacia oleracea L.) cultivation. J. Soils Sediments. 14, 44-59.

Hassan W., David J., Bashir F. 2014a. ACCdeaminase and/or nitrogen fixing rhizobacteria and growth response of tomato (Lycopersicon pimpinellfolium Mill.). J. Plant Interact. 14, 869882.

Hassan, W., Bano, R., Bashir, F., David, J. 2014b. Comparative effectiveness of ACC-deaminase and/or nitrogen fixing rhizobacteria in promotion of maize (Zea mays L.) growth under lead pollution. Environ. Sci. Pollut. Res. 21, 1098310996.

Hassan, W., David, J., Abbas, F. 2014c. Effect of type and quality of two contrasting plant residues on $\mathrm{CO}_{2}$ emission potential of Ultisol soil: implications for indirect influence of temperature and moisture. Catena. 114, 90-96.
Hassan, W., Chen, W., Cai, P., Huang, Q. 2014d. Estimation of enzymatic, microbial and chemical properties in Brown soil by microcalorimetry. J. Therm. Anal. Cal. 116, 969988.

Hassan, W., Bano, R., Khatak, B.U., Hussain, I., Yousaf, M., David, J. 2014e. Temperature Sensitivity and Soil Organic Carbon Pools Decomposition under Different Moisture Regimes: Effect on Total Microbial and Enzymatic Activity. CLEAN - Soil, Air, Water doi:10.1002/clen.201300727.

Hayat, R., Ali, S., Amara, U., Khalid, R., Ahmed, I. 2010. Soil beneficial bacteria and their role in plant growth promotion: a review. Ann. Microbiol. 60, 579-598.

Honma, M., Shimomura, T. 1978. Metabolism of 1-aminocyclopropane-1-carboxylic acid. Agr. Biol. Chem. 42, 1825-1831.

Mayak, S., Tirosh, T., Glick, B.R. 2004. Plant growthpromoting bacteria confer resistance in tomato plants to salt stress. Plant Physiol. Biochem. 42, 565-572.

Mia, M.A.B., Shamsuddin, Z.H., Wahab, Z., Marziah, M. 2010. Effect of plant growth promoting rhizobacterial (PGPR) inoculation on growth and nitrogen incorporation of tissue-cultured Musa plantlets under nitrogen-free hydroponics condition. Aus. J. Crop Sci. 4, 85-90.

Nadeem, S.M., Zahir, Z.A., Naveed, M., Arshad, M., Shahzad, S.M. 2006. Variation in growth and ion uptake of maize due to inoculation with plant growth promoting rhizobacteria under salt stress. Soil Environ. 25, 78-84.

Nakano, Y., Azada, K. 1987. Purification of ascorbate peroxidase in spinach chloroplasts: its inactivation in ascorbate depleted medium and reactivation by monodehydroascorbate radical. Plant Cell Physiol. 28, 131-140. 
Premono, H.M.E., Moawad, A.M., Vlek, P.L.G. 1996. Effect of phosphate-solubilizing Pseudomonas putida on the growth of maize and its survival in the rhizosphere. Indonesian J. Crop Sci. 11, 1323.

Sarwar, M., Arshad, M., Martins, D.A., Frankenberger, Jr. 1992. Tryptophan-dependent biosynthesis of auxins in soil. Plant Soil. 147, 207-215.

Schalchli, H., Pardo, F., Hormazábal, E., Palma, R., Guerrero, J., Bensch, E. 2012. Antifungal activity of wheat root exudate extracts on Gaeumannomyces graminis var. Tritici growth. J.Soil Sci. Plant Nut. 12, 329-337.

Shaharoona, B., Arshad, M., Zahir, Z.A., Mahmood, M.H. 2003. 1-aminocyclopropane-1-carboxylate (ACC) enrichment: An effective approach to screen plant growth promoting rhizobacteria for maize. Pak. J. Agri. Sci. 40, 126-132.
Stefan, M., Munteanu, N., Stoleru, V., Mihasan, M 2013. Effects of inoculation with plant growth promoting rhizobacteria on photosynthesis, antioxidant status and yield of runner bean. Rom. Biotech. Letter. 18, 2.

Van-Schouwenberg, J.C.H., Walinge, I. 1973 Methods of analysis for plant material. Agri Univ Wageningen, the Netherlands.

Wollum II, A.G. 1982. Cultural methods for soil microorganisms. In: methods of soil analysis, part 2: chemical and microbiological properties. Page AL (Eds), Agronomy No 9, ASA, Madison, WI, pp. 781-802.

Zafar-ul-Hye, M., Zahir, Z.A., Shahzad, S.M., Naveed, M., Arshad, M., Khalid, M. 2007. Preliminary screening of rhizobacteria containing ACC-deaminase for promoting growth of lentil seedlings under axenic conditions. Pak. J. Bot. 39, 1725-1738. 